\title{
Logit Analysis in Exporting Decision of Fisheries Company
}

\section{Popy Novita Pasaribu}

Universitas Ibn Khaldun Bogor, Indonesia

E-mail:pnovita@yahoo.com

\section{Hendri Tanjung}

Universitas Ibn Khaldun Bogor, Indonesia

E-mail: hendri.tanjung@gmail.com

Doi:10.5901/mjss.2015.v6n5s5p183

\begin{abstract}
The purpose of this study is to determine the quantitative methods for export or domestic selling of fishery commodities as well as the factors influencing this decision for newly set up company. Data were taken from 50 companies producing fishery commodities that both export and domestic selling. Three models analyzed were LPM, Log LPM and Logit. Based on the MacKinnon, White and Davidson (MWD) test on the LPM with linear model and LPM with log linear model, the preferred one was the LPM with log linear models. However, considering the error rate in LPM model, a recommendation is to use the Logit model. Based on the estimation results using the Logit model, the most significant factor affecting fishery companies' decision to export is the fisheries product standardization.
\end{abstract}

Keywords: Exporting Decision; Fisheries Commodities; LPM;Logit Model

\section{Background and Objectives}

Exporting generates various benefits for companies (Andersen, 1993). Indonesia, as a member of WTO and in regional scope also a member of ASEAN, have participated in global and regional economy which demand cheaper, faster and better products. Some reasons to export are as follows: an increase in sales and profits; gain market share globally and regionally; reduction of dependence on the domestic market and stabilization of market fluctuations. The direct benefits of exporting is the opportunities to expand market share; production increase when the capacity is underutilized for serving only domestic market; and less dependencies to the domestic sales or domestic market stagnation (Mangistae and Pattillo, 2004).However, similar to domestic selling, exporting also pose some degree of risks, for example: sales are unable to meet the market demand; unanticipated tougher competition; specific risks associated with exporting; limitation or restriction of profit repatriation from the target country; currency fluctuation that will reduce or eliminate profitability or even loss; and also the risk of product being unaccepted in the foreign market (Richardson and Rindal, 1995). Since Indonesia, a maritime country which exports fishes and sea products, it is very important to boost this kind of export for Indonesian economy. The questions are: which factors influenced the export decision of fisheries companies? Which appropriate model to use? With this background, the study is conducted.

The purposes of this study are to analyzewhich factor has significant influence on the decision to export or to sell in domestic market for a prospective fisheries commodity company.Other purpose is to select a proper quantitative method for the export decision

\section{Literature Review}

Jaaby and Esemu (2014) examine the sources of financing and its impact on exports and research and development (R\&D) in the Uganda fish industry. The study adopted a mix approach using qualitative and quantitative to assess the source of financing and its impacts on exports and R\&D. The findings reveal that fish enterprises's access to formal financial credit is limited to supporting fish production, exports and R\&D.

Anas (2013) assessesthe role of firm's size in the Indonesian manufacturing exports. The analysis is based on a panel data of manufacturing plants from 2001 to 2007. In estimating the role of firm's size in exports, this study borrows the supply response function model of Roberts and Tybout (1997), where sunk-cost and other determinants incorporated 
in the model. Other determinants incorporated in the model are labour productivity, labor quality, ownership, sectoral share of exporters and regional share of exporters. The result shows that small firms have lower probability to export compared to other firms. Interestingly, however, small firms have higher export intensity compared to medium-sized firms.

Fuesanta (2010) build a predictive model of the export behaviour of small and medium sized firms in Spain. She carries out a closer examination of the differences between exporters according to their commitment to the international market. Once the main disparities are identified by using mannwhitney U-test, a logistic analysis based upon data collected from small and medium sized manufacturing firms is conducted in order to construct a classificatory model.

Karen and Sandi (2014) examine four factors which influence export activity for women business owners in Atlantic Canada by using logit model. The factors are entrepreneurial orientation, marketing strategy development, engagement in research and development, and technology investment. The result is the only factor that had a statistically significant influence on exporting was investment in research and development (R\&D).

Logit model has been used by previous studies as decision model. Filstrup et.al., (2014) compare two non linear models and one log linear model to search relationship between chlorophyil and total phosporus in lakes in the US. Using data set from 2105 temperate lakes across 35 ecoregions, they find that the two non linear models fit the data better than the log linear model. Thompson et.al., (2012) use logit model to determine relationship between sharing country food and food security in 14 northern Manitoba communities in Canada. The model predicts that rates of food insecurity for a community with a country foods program and with access to public transit and roads at $95 \%$ would be lower than the Canadian average of $92 \%$.

Odegoun et.al., (2008) apply logit model in adoption decision in aquaculture industry. They estimates and explains the parameter of adoption process of hybrid clarias by fish farmers in Lagos state Nigeria. They find that the knowledge, accuracy and technical responsibilities become more significant to the success of the technology as well as aquaculture industry.Mandleni and Anim (2014) apply logit model to determine the level of support received by co-operative in all the nine provincies of South Africa. Information was used from 266 co-operatives across the country. The results of the study indicated that support for co-operatives was lacking during the period of study..

The literature reviews shows that some authors analyze factors influencing export decision. Anas (2013) analyzes some factors influencing exports such as labour productivity, labor quality, ownership, sectoral share of exporters and regional share of exporters, whereas Jaaby and Esemu (2014) examines only one factor i.e., the sources of financing and its impact on exports. Logit model is also used by some author to help decision making in some aspect of industry or business and to predict or explain some relationship. The authors who use logit model in adoption decision are Odeagun et.al. (2008). The authors who use logit model in predicting, determining, and explaining some relationships are Thompson et.al., (2012), Fuesanta (2010), Mandleni and Anim (2014), and Karen and Sandi (2014). Some authors compare the linear and log linear model to explain the relationship between variables, i.e., Christopher Filstrup et.al. (2014).

We conclude from several works before, that logit model oftenly used to predict, determine, and to explain factors, and also to help decision making. Based on that, we use logit to help decision on export activity in fisheries companies. Earlier literatures also show some variables influencing export decision, i.e., labour productivity, labor quality, ownership, sectoral share of exporters, regional share of exporters, and the sources of financing. In this study, we use others factors to explain the export decision of fisheries company in Indonesia.

\section{Research Method}

\subsection{Data Gathering and Data Analysis}

Data are collected from the companies that produce fishery commodities destined for either export or domestic. Selection of the study area is determined based on the results ofFisheries Companies Statistic 2013 (BPS, 2014), taken ten of the biggest areas of fishery commodities. From the ten regions were taken 50 respondent companies producing fishery commodities as determined by purposive sampling. We use purposive sampling because we cannot apply random sampling in the sense that we must know the condition of the companies earlier. The results of the data collection of the 50 respondents of fishery commodities companies that export or sell in domestic market processed using SPSS 21 statistical software.

Econometric model is used to analyze the factors that significantly influence company decision to export. Some alternative quantitative models in this study consists Linear Probability Model (LPM) using linear regression models as well as non-linear regression models or Log LPM and QualitativeDependentVariable (QDV) (John \& Nelson, 
1984). LPM approach and QDV approach are selected due to dependent variables used to answer the research objectives is a dummy variable showing the probability of fishery commodity export or domestic selling.

LPM has two alternative approaches which are linear regression model and log linear regression model. Whereas there are three alternative approaches in QDV namely Logit Model, Probit Model and Tobit Model (Doyle, 1977). The difference in these models lies in the assumption of differences in the distribution of opportunities (the dependent variable), which is essentially unobservable. In the quantitative model selection, it is indicated that QDV model would be more appropriate as compared to the LPM, which is usually expressed in the form of multiple linear regression. Since there is possibility of having the alleged value of the dependent variable value greater than one or less than zero in the multiple regression model used in the opportunities analysis for the company to export fishery commodity, it does not fit with the concept of the dependent variable interpreted as a probability. Therefore the Logit model is selected to overcome this circumstances (Egger \&Kesina, 2013). Doyle (1977), Thompson et.al. (2012), Fuesanta (2010), Mandleni and Anim (2014), and Karen and Sandi (2014) and has used the logit model in similar situation.

\subsection{Operational Variables Definition}

In the LPM and Logit model as described previously, the dependent variable is the probability of company to export their fishery commodity. Gripsrud (1990) has identified determinats of export decisions and attitudes. In this paper, the independent variables for business characteristics analysis include the company capital (CAP), company scale (SIZE). The variables CAP and SIZE are implication of the assumption that the probability of company to export is increasing along with the increase of their capital and business scale, therefore the variables expectation is positive $(+)$. The company's business scale is identified by the number of labors employed. Another variables is the company age (AGE), this variable is identified as the difference between the current year with the year of company established. Another variable is the Product Standardization (STND) (Andersen, 1993). This dummy variable is identified by classifying if the company applies international standard in their production process $(S T N D=1)$ or not.

The use of new technology is also included as one of the variables. Therefore dummy variable with value 1 is used if the company applied new technology development and value 0 if not. Variable R\&D activity (RD) is included as an influencing factor as positive correlation between research activity and probability of company preference to export their production to international market. The dummy variable used is value 1 if the company conducts R\&D activities and introduced new innovation process and 0 if not. The variable trading cost (TRC) is included considering the distance between producer and trading locations. This variable is identified as the cost associated with the transportation to the trading location, if the trading cost is higher then the probablity of the company to export is less, therefore this variable has negative expectation (-).

Variable Market Demand is identified with the GDP of the target country since the GDP indicates the ability to absorp the product in the international market. If the market demand is higher then the probability of company to export is higher, therefore this variable has positive expectation (+). The price difference (PRICE) variable has positive expectation sign $(+)$ as well since this variable is measured as the price difference percentage between domestic selling price and international export price. The last variable is the exporter committing common mistakes (FAIL) (Andersen,1993). According to the nine common mistakes possible, this variable is identified using the dummy variable which is Committing No Common Mistake (FAIL=1) and Commiting Common Mistake (FAIL=0).

\section{Results and Discussion}

\subsection{LPM Model}

The estimation results using the LPM, Log LPM and Logit modelsare presented in Table 1. It shows that $\mathrm{R}^{2}$ between the actual dependent variable (observation) values and the alleged dependent variable value (estimated from the equation) for LPM, Log LPM and Logit consecutively are $0.627 ; 0.643$ and 0.638 . For the cross-section data, as used in this analysis, the values of the determination coefficient $\left(R^{2}\right.$, which is the model's goodness of fit measure) are quite large. Log LPM model has the largest goodness of fit as compared to the LPM and the Logit models.

As the first step, the selection of quantitative method, between the LPM and the Log LPM, is using six steps MWD test. The hypothese for the MWD test is stated as follows: $\mathrm{nH}_{0}$ : Linear Model and $\mathrm{H}_{1}$ : Log-Linear model. The regression results for the linear and log linear models are as follows:

$$
\hat{Y}=-0.367-0.000000 \text { CAP }+0.000109 \text { SIZE }+0.0040 \text { AGE }+0.636 \text { STND }-0.065 \text { NEWT }
$$


+0.234 RD +0.000276 TRC +0.000253 GDP - 0.0033 PRICE + 0.292 FAIL

$\mathrm{F}=6.55 ; \mathrm{R}^{2}=0.627$

$\hat{Y}=-1.20+0.0175$ LnCAP -0.068 LnSIZE +0.134 LnAGE +0.639 STND

- 0.066 NEWT + 0.305 RD + 0.160 LnTRC - 0.052 LnGDP + 0.014 LnPrice

+0.330 FAIL

\section{$F=7.02 ; R^{2}=0.643$}

The regression results indicate that both models, the linear and log linear, can provide good estimate. This parameter is shown by using the F-test, as conclusion: both models are sufficient to determine export decision of fishery commodity.

In order to determine which model is selected using MWD test, first the model hypothesis is that the model is linear. The next step is to calculate the value of $Z$ by performing regression using the $Z$ value, and the regression result obtained is as follows:

$$
\begin{aligned}
& \hat{Y}=-0.091-0.000000 \text { CAP }+0.00146 \text { SIZE }-0.0379 \text { AGE + 0.537 STND }-0.110 \text { NEWT } \\
& -0.010 \text { RD +0.000169 TRC + 0.00178 GDP }-0.0225 \text { PRICE + 0.163 FAIL } \\
& -4.47 Z_{1} \\
& \mathbf{F}=\mathbf{9} .33 ; \mathbf{R}^{2}=\mathbf{0 . 7 3}
\end{aligned}
$$

\begin{tabular}{|c|c|c|c|c|c|c|c|c|c|c|}
\hline \multirow{3}{*}{ Variable } & \multicolumn{3}{|c|}{ LPM Mode1 } & \multicolumn{3}{|c|}{ Logit Model } & \multirow{3}{*}{ Variable } & \multicolumn{3}{|c|}{ Log LPM Model } \\
\hline & \multirow{2}{*}{$\begin{array}{l}\text { Reg. } \\
\text { Coeff. }\end{array}$} & \multicolumn{2}{|c|}{ Asimptotic } & \multirow{2}{*}{$\begin{array}{c}\text { Reg. } \\
\text { Coeff. }\end{array}$} & \multicolumn{2}{|c|}{ Asimptotic } & & \multirow{2}{*}{$\begin{array}{l}\text { Reg. } \\
\text { Coeff. }\end{array}$} & \multicolumn{2}{|c|}{ Asimptotic } \\
\hline & & Std Errot & t-Ratio & & Std Error & $\mathbf{P}$ & & & Std Erro & t-Ratio \\
\hline Constant & -0.3665 & 0.21 & -1.75 & -7665 & 3788,0000 & 0.043 & Constant & -1204 & 1204 & -1 \\
\hline CAP & 0,0000 & 0,0000 & -0.62 & $-1.517 \times 10^{-11}$ & $6.862 \times 10^{-10}$ & 0.982 & LnCAP & 0.01746 & 0.0748 & 0.23 \\
\hline SIZE & 0.0001 & 0.0058 & 0.19 & -0.00135 & 0.0107 & 0.899 & LnSIZE & -0.068 & 0.1088 & -0.63 \\
\hline AGE & 0.0039 & 0.0161 & 0.25 & 0.0562 & 0.2342 & 0.81 & LnAGE & 0.1338 & 0.1338 & 0.94 \\
\hline STND & 0.6360 & 0.1474 & 4.31 & 4205 & 1715 & 0.014 & STND & 0.639 & 0.1524 & 4.19 \\
\hline NEWT & -0.0655 & 0.1438 & -0.46 & -0.35 & 1855 & 0.851 & NEWT & -0.0663 & 0.1482 & -0.45 \\
\hline RD & 0.2338 & 0.1303 & 1.79 & 2049 & 1533 & 0.182 & RD & 0.3046 & 0.1367 & 2.23 \\
\hline TRC & 0.0003 & 0.0002 & 1.29 & 0.0080 & 0.0065 & 0.22 & LnTRC & 0.1604 & 0.101 & 1.59 \\
\hline GDP & 0.0003 & 0.0002 & 0.85 & 0.0004 & 0.0047 & 0.93 & LnGDP & -0.0518 & 0.1145 & -0.45 \\
\hline PRICE & -0.0032 & 0.0167 & -0.2 & -0.0942 & 0.2628 & 0.72 & LnPrice & 0.0136 & 0.1043 & 0.13 \\
\hline FAIL & 0.2919 & 0.1311 & 2.23 & 2536 & 1629 & 0.122 & FAIL & 0.3305 & 0.1268 & 2.61 \\
\hline & \multicolumn{3}{|c|}{$\mathrm{R}^{2}$ observed - predicted $=0$} & \multicolumn{3}{|c|}{$\begin{array}{l}\mathrm{R}^{2} \text { observed - predicted }=0.638 \\
\text { Log-Likelihood }=-11.475\end{array}$} & & \multicolumn{3}{|c|}{ observed - predicted $=0.6$} \\
\hline
\end{tabular}

Table 1. Factors influencing the decision to export fishery commodity

$Z_{1}$ coefficient has a value of $T$ calculated $=-3.81$ and $P=0.000$. $T$ is a statistical t-test to evaluate the significance of each independent variable on the dependent variable. If the absolute value of $T$ ( $t$ calculated) is larger then the influence of the independent variable on dependent variable is more significant, which is a condition of $T$ is greater than $t$ table value. The $t$ table value for $\mathrm{t}_{(0.05 ; 40)}=1.684$ so that $|T|>t_{\text {tabel }}$. Because $Z_{1}$ is statistically significant the hypothese $\mathrm{H}_{0}$ is rejected with conclusion that the model is linear.

The next step is to reverse the hypothese that the model is log linear, regression results obtained by using $Z_{2} v a l u e$ $\left(Z 1=Z 2\right.$, since $Y$ is a dummy variable that does not require log conversion to get $Z_{1}$ or antilog conversion to get $Z_{2}$ ):

$$
\begin{aligned}
& \hat{Y}=-1.87+0.0734 \text { LnCAP }-0.166 \text { LnSIZE + 0.289 LnAGE + 0.619 STND } \\
& -0.036 \text { NEWT + 0.404 RD + 0.240 LnTRC }-0.232 \text { LnGDP + 0.096 LnPrice } \\
& +0.384 \text { FAlL + } 1.57 \text { Z2 } \\
& \mathbf{F}=6.52 ; \mathbf{R}^{2}=\mathbf{0} .654
\end{aligned}
$$

The Coefficient $Z_{2}$ has the $T$ calculated $=1.08$ and $P=0.287$. Thus obtained $|T|<t_{\text {tabel }}$. Because $Z_{2}$ is statistically insignificant then the conclusion is to accept the hypothese that the model is log linear.

Based on the MWD test the Log LPM model is chosen. Log LPM model has $R^{2}=0.643$. $R^{2}$ is the determination 
coefficient, it is interpreted that the value of 0.643 means that $64.3 \%$ variation in the decision to export fishery commodity can be explained by the model estimation. The remaining $35.7 \%$ is explained by the error components. T value of the independent variables indicates that there are three significant independent variables ( $\mathrm{t}(0.05 ; 40)=1,684$ or $|T|>t_{\text {table }}$ ) influencing the dependent variables, namely the standardization of products (STND), the use of R\&D results (RD) and company commiting common exporting mistakes (FAIL).

\subsection{Alternative to LPM: Logit Model}

As consideration there are problem intrinsic to LPM model, such as (1) Non-normality of $u_{i}$, (2) hetero-skedasticity of $u_{i}$, (3) Possibility of $Y_{i}$ having value beyond 0-1 and (4) relatively low $R^{2}$ value (John and Nelson, 1984). There are workaround to these problems, for example, we can apply WLS to address the heteroscedasticity problem or increase the sample size to minimize the problem of non-normality. Estimation resultindicates there are $\hat{Y}_{i}$ values outside the probability interval 0-1, which is either a negative value or a number greater than 1.

Furthermore John and Nelson (1984) stated that The basic problem with LPM is that logically it is not an attractive model, sinceit assumes $P_{i}=E(Y=1 \mid X)$ increases linearly along the $X$, i.e.the marginal effect of $X$ remains constant. What is needed is a probability model that choose two things: (1) if $X_{i}$ increased, $P_{i}=E(Y=1 \mid X)$ increased with the value between 0 to 1 , and (2) the relationship between $P_{i}$ and $X_{i}$ can be nonlinear, "close to 0 with slowing rate when $X_{i}$ are getting smaller and closer to 1 with slowing rate when $X_{i}$ are getting bigger. The desired model can be as illustratedsigmoid curve (s-shaped) that the probability is between 0 and 1 with in a non linear variation to $X$.

Therefore, eventhough the log LPM based MWD test is appropriate to be used as a model to determine the chance of company to export fishery commodity, however LPM has intrinsic problem. Thereforethe next best alternative is to use QDV i.e. logit model.

Logit estimation, refer to Table 1, it shows only one variable that significantly influence the decision of exporting fishery commodity products and that variable is the product standardization variable (STND). STND has a $P$ value of 0.014 which is smaller than the value of $a=0.05$ which showed enough evidence to say that STND parameter is not equal to zero. STND coefficient worth 4,205 which suspect the change in the log of P export / P domestic when company does not standardize their products as compared to company does standardize their products, and the other variables constant.

As shown in the Table 1, based on the Logit model, among all the independent variables, only one that statistically significant affecting the fishery commodity export opportunities, namely variable products standardization (STND). This suggests that the product standardization used for fishery commodity directly reflects the high opportunities to export the commodity. This suggests that the products standardization in the era of the global economy is essential in doing export to provide a variety of benefits for the company, especially in fisheries product. Through products standardization, access to new consumer markets can be achieved. Therefore productsstandardization is a pre-requisite to compete in the global market, where through the World Trade Organization (WTO) tariff and non-tariff barriers has been eliminated. Only products that can comply with the international standards can compete in the global market.

Companies that have been certified on the international standardshave higher chance to success in exporting their products. The international standard certification contributes to the increase in sales and profits; gaining global market share; reduction of dependence on the domestic market; stabilization of market fluctuations; optimization of the entire production capacity; and strengthening competitiveness.

\section{Conclusions and Recommendations}

\subsection{Conclusions}

LPM model selection between the linear model and the log linear models using test MacKinnon, White and Davidson (MWD). MWD test results prove that the log linear regression model is more precise than the linear regression model. However, the selection of a quantitative method to prove that the model would be more appropriate log linear probability model (LPM). This is because the multiple regression model used in the analysis of the opportunities for business and exports of fishery commodities, there is a suspicion of the dependent variable value is greater than one or less than zero, so it is not in accordance with the concept.

In this article the model used is a logit model. Logit model is considered appropriate with demonstrated the value of $\log$ likelihood $G=34.355$ with a value of $P=0.000$. Whereas $R^{2}$ obtained from the actual value of the dependent variable 
(observation) and the alleged value of the dependent variable with a value of 0.638 .

Fishery commodity export decision was influenced primarily by a factor of product standardization. Product standardization coefficient showed statistically significant and positive effect on export opportunities. Standardization of products is a pre-requisite to be able to compete in the global market, so according to this study the standardization of products is the only variable significantly affecting company's decision to export.

\subsection{Recommendations}

Further studies are needed to enhance the analysis of the factors that influence the decision to export, for example using the Stage/Tiered analysis. First step is to analysis the exporting sunk cost. Second step is to analyze the business characteristics as proposed in this research. The third step is to analyze profitability. Lastly, an analysis of the factors that affect the chances of commiting mistake in exporting.

\section{References}

Adegoun et. Al. (2008) Application of logit model in adoption decision: a study of hybrid clarias in lagos state Nigeria. American-eurasian J. Agric. \& environ sci., 4(4): 468-472

Anas, Titik (2013), missing middle in the Indonesian manufacturing exports, proceeding international conference. P. 19.

Andersen, O. (1993). On the internationalization process of firms: a critical analysis. Journal of international business studies, 209-231.

BPS, (2014), Statistik Perusahaan Perikanan 2013. [Online] Available: http://www.bps.go.id/index.php/publikasi/454\# (December 10, 2014)

Doyle, P. (1977). The application of probit, logit, and tobit in marketing: A review. Journal of Business Research, 5(3), 235-248.

Egger, P., \&Kesina, M. (2013). Financial constraints and exports: evidence from Chinese firms. CESifo Economic Studies, 59(4), 676706.

Filstrup et.el. (2014) Regional Variability among nonlinear chlorophyll-phosporus relationships in lakes.Limnol, oceanogr., 59(5) 2014, 1691-1703, association for the sciences of limnology and oceanography, inc.

Fuesanta, Maria Jesus Ruiz (2010), a predictive model of the export behaviour of small and medium sized firms: an application to the case of castilla-La Mancha. Cuadernos de Gestion Vol. 11, No. 2, pp. 89-110.

Gripsrud, G. (1990). The determinants of export decisions and attitudes to a distant market: Norwegian fishery exports to Japan. Journal of International Business Studies, 469-485.

Jaaby, Seeku A, and Timothy Esemu (2014), Fish Enterprise Financing and its Impact on exports and Research and Development: The case of Uganda's Fish Industry. Institutions and Economics, Vol. 6, Issue 3, October 2014, pp. 35-59.

John H. Aldrich and Forrest D. Nelson. (1984). Linear probability, logit, and probit models (Vol. 45). Sage.

Karen, Blotnicky and Findlay-Thompson Sandi (2014), Entrepreneurial orientation and innovation investment: A comparative analysis of factors leading to exporting among Atlantic Canadian Women Business Owners. ASBBS ejournal; vol. 10, No. 1 : Summer 2014.

Mandleni, B. Nkonki- and F.D.K. Anim, Determining factors of support for co-operatives in South Africa. J Hum Ecol, 47(2): 171-174 (2014).

Mangistae, T. and Pattillo, C. (2004). Export Orientation and Productivity in Sub-Saharan Africa. IMF Staff Papers. Vol.51, Iss.2, Washington.

Richardson, D. and Rindal, K. (1995). Why Export Really Matter. Institute for International Economics Publications and Manufacturing Institute, Washington DC.

Roberts, M. J., \&Tybout, J. R. (1997). The decision to export in Colombia: an empirical model of entry with sunk costs. The American Economic Review, 545-564.

Thompson, et.al. (2012) Community Development to feed the family in northern Manitoba communities: evaluationg food activity based on their food souvereignity, food security, and sustainable livelihood outcomes.Canadian Journal of Nonprofit and social economy research vol. 3, No. 2, Fall/automne, 2012, pp.43-66. 